\title{
TEXTO, ENCENAÇÃO E CINEMA
}

Rafael Conde*

*rafael@rafaelconde.art.br

Professor do Departamento de Fotografia, Teatro e Cinema da EBA/UFMG. Doutorado em Artes Cênicas pela Mestre e Performance Sudies na New York University. Econômicas pela UFMG. Entre seus trado em Ciècias conomicas pela UFt. Eusika A Hora destacam-se: Uakti, Musika, A Hora Vagabunda, Françoise, Samba-Canção, Rua da Amargura, A Chuva nos Telhados Antigos e Fronteira (prêmio de roteiro

RESUMO: A presença do roteiro cinematográfico como obra autônoma tem sido sempre problematizado no cinema e por outros campos como o teatro e a literatura. Para o cinema, o roteiro sempre foi um elemento de passagem, algumas vezes negado como origem da verdadeira autoria do filme e outras questionado como elemento de controle sobre a vocação documentária do filme. Nas irrestritas formas de escrita do roteiro, para além da aceitação de seu status de obra pronta, podemos encontrar diferentes poéticas e subjetividades diante das inúmeras formas de encenar o filme.

PALAVRAS-CHAVE: Roteiro; Cinema; Teatro; Literatura Encenação.
ABSTRACT: The literary character of the screenplay has always been questioned in film and other fields such as theater and literature. For film, the script was always an element of passage, sometimes denied as the source of true authorship of the film, sometimes questioned as an element of control over the film documentary vocation. However, in its unrestricted forms of writing, we can find different poetics and subjectivities before the countless ways of staging the film.

KEYWORDS: Screenplay; Cinema; Theater; Literature; Staging. 
"Tudo o que não invento é falso"

Manuel de Barros

No esboço de um roteiro cinematográfico, momento embrionário de um projeto de filme, já podemos antever uma certa interlocução entre o olhar do encenador, uma técnica e uma forma de encenação no cinema. Percebemos de antemão no corpo do texto, no caso de um filme mais autoral, que o encenador prefere uma divisão de cenas ainda sem um detalhamento técnico rigoroso. Um primeiro indício de um trabalho mais livre de fragmentação das cenas ou decupagem no set, provavelmente a ser repensado depois de um ensaio com a câmera, a partir do contato entre o personagem, já sedimentado no ator, e o imprevisto do espaço de uma nova locação. Ou mesmo um indício da aceitação de uma incorporação ao jogo do filme da contribuição natural do acaso, que pode desenhar o céu com um tipo de nuvens no momento da ação ou uma luz que imprimirá mais dramaticidade, caso trabalhada através do seu reflexo no calçamento de pedra depois da chuva, podemos ilustrar. No roteiro cinematográfico já antevemos a proposta de um ritmo e uma montagem, um certo tempo trabalhando sobre a história e a paisagem. Podemos prever uma certa linearidade na narrativa, com um certo encadeamento dramático.

O roteiro traz em si o projeto de interlocução do realizador cinematográfico com a construção da cena, com o desenho de um conflito, com a proposta de trabalho do ator e sua colocação no espaço e tempo do filme. Um tipo de roteiro que antecipa as maneiras e opções de trabalhar o material fílmico, a fragmentação da cena e a montagem; e de forma mais abrangente, apresenta o grau de realismo ou ilusão na sua abordagem da trama e outros paradigmas e variáveis operatórias na realização audiovisual que são alguns elementos básicos de encenação. Mas vale ressaltar que, mesmo encontrando no roteiro uma estrutura, uma história 'imaginada' e uma dramaturgia, não existe dúvida de que o 'filme escrito' ainda é um início de um processo e, certamente, não é ainda a etapa determinante da encenação no cinema. Para JeanClaude Carrière,

objeto efêmero: o roteiro não é concebido para perdurar, mas para se apagar, para tornar-se outro. Objeto paradoxal: de todas as coisas escritas o roteiro é a que contará com o menor número de leitores, talvez uma centena, e cada um desses buscará nele o seu próprio alimento: o ator, um papel; o produtor, um sucesso; o diretor de produção, um percurso inteiramente traçado para a fixação de um plano de trabalho. ${ }^{1}$

O diretor busca no roteiro a estruturação ou certo grau de controle sobre uma cena, a visão sobre uma dramaturgia, uma montagem e encenação prevista nas entrelinhas do próprio texto. A partir de um roteiro já podemos estabelecer
1. CARRIÈRE. A linguagem secreta do cinema, p. 11.
EM TESE
BELO HORIZONTE
v. 20
N. 3
SET.-DEZ. 2014
CONDE. Texto, encenação e cinema
P. 154-162

\section{Crítica Literária, outras Artes e Mídias}


2. FIELDS. Manual do Roteiro, $\mathrm{p}$. 14. uma imagem ainda não materializada do filme - o roteiro é a primeira etapa de um processo, uma passagem.

Numa proposta de filme narrativo clássico, como por exemplo em um roteiro negociado por um grande estúdio norte-americano, dentro da sua construção dramática e técnica moldadas por padrões (ou regras) do roteiro comercial, com uma linguagem fluida e apelos para o grande público, já antevemos um filme com determinada linearidade e transparência narrativa, blocos dramáticos (apresentação-confrontação-resolução) ${ }^{2}$ bem definidos, uma velocidade ou ritmo, também com uma interlocução com a cena pré-estabelecida. Nesse roteiro ou projeto de filme, um produtor provavelmente contratará o diretor tanto por seu 'valor de mercado' (um nome festejado pela mídia e realizador de filmes de grande bilheteria), quanto pelo seu mérito técnico de encenador cinematográfico. Dentro dessa estrutura in dustrial, com raras exceções, não interessa o diretor como autor e inventor. Não existe espaço para improvisos e nem para novos 'finais'. Vale o que está escrito, vale o que lhe é pedido por um texto técnico. Existe no roteiro do filme narrativo clássico industrial uma 'neutralidade' de encenação, dado que ele não se espelha na subjetividade e estilo de nenhum encenador em particular, e, ao mesmo tempo, impõe uma estrutura de encenação rígida, dentro dos padrões reconhecidos pela indústria, inclusive com um 'happy end', visando atingir o maior número de pessoas e assegurar o retorno financeiro esperado.

No campo de trabalho do cinema, a presença do texto escrito se manifesta diferentemente do teatro, outro campo onde uma intermediação do texto é problematizada pela sua forma de passagem, de transitoriedade. A sacralização e permanência de alguns textos-peças a serem tornados 'cenas' teatrais ainda hoje e a efemeridade dos roteiros cinematográficos são formas distintas de estabelecer diferentes valorações diante de sua representação e diferentes valorações diante do caráter literário de sua escrita, como acontece na tradição de cada uma dessas duas práticas. Essa discussão gravita também em torno da permanência da imagem técnica (de sua possibilidade de reprodução e circulação) e do efêmero do encontro teatral. O que interessa aqui é determinar que a encenação ou 'projeto de representação' presente no roteiro é que estrutura a grande maioria dos filmes, tanto em um trabalho com propostas industriais quanto na obra de autor, onde o próprio realizador, criador e investigador, é o agente de todo o processo.

O texto, roteiro ou mesmo 'peça cinematográfica' como já foi chamado, assume determinado grau de liberdade de acordo com cada projeto de filme; sendo que um projeto de filme, e portanto o roteiro, é também, resultado das interrelações entre a subjetividade do realizador (uma poética ou

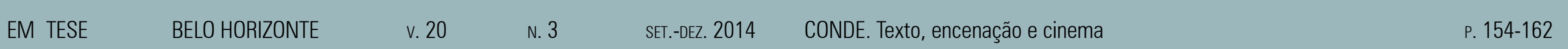

\section{Crítica Literária, outras Artes e Midias}


3. ROUBINE. Introdução às grandes teorias do teatro, p. 144. olhar sobre o cinema e o mundo), um aparato (uma economia, uma estrutura, uma técnica) e uma forma de trabalhar a cena. A variação desse grau de liberdade presente no texto dramático é determinante também sobre a cena do teatro e determinante nas transformações de sua bem mais longa história.

Jacques Copeau, citado por Jean-Jacques Roubine, ao estabelecer uma hierarquização de autoria no teatro entre o dramaturgo e o encenador, afirma que "[o texto] é para o drama o que o caroço é para a fruta, o centro sólido em torno do qual vêm se organizar os outros elementos". ${ }^{3}$ No teatro clássico, diz Roubine, encenar é antes de tudo pôr-se à escuta do texto. A representação não seria um fim em si mas apenas um gesto iluminador do texto, uma caixa de ressonância para o texto. Claro, essa diferença de valoração entre texto e representação no teatro varia substancialmente ao longo de sua história, sabendo-se mesmo um dos agentes determinantes na transformação dos procedimentos de encenação. Já no campo do cinema, desde sua invenção, devido talvez a questão primeira da presença da câmera e sua intervenção sobre a cena, relegou o texto a um plano secundário em relação aos modos de representação e ao papel de seu encenador. Não obstante, podemos afirmar que diferentes diretores encenando o mesmo roteiro criariam tantos filmes diferentes quantas são diferentes as peças encenadas a partir de um mesmo Hamlet. Na práxis cinematográfica, o roteiro é projeto, uma história, um plano de trabalho, peça dominante no filme narrativo clássico industrial e simples referência no cinema autoral, ou mesmo inexistente em um drama mais recente, mas sempre fadado ao desaparecimento ou esquecimento. A questão de sua presença como obra autônoma, sua sacralização, nunca foi centro de grandes discussões e transformações.

A propósito da importância do texto cinematográfico ou roteiro, de sua possível autonomia literária ou da sua presença como cinema por si próprio, também varia em sua curta história. Temos a questão da importância do texto no filme de autor, a presença discreta e controversa do roteiro dentro da tradição da encenação documentária, temos as práticas em torno do exemplo da frase-manifesto: 'câmera na mão e uma ideia na cabeça', e muitas outras possibilidades de pensar a presença do texto no cinema. Temos também as questões que envolvem a polêmica que retorna de tempos em tempos, em torno da questão da autoria do filme ou de quem realmente inventa o filme: roteirista ou diretor? Polêmica que, há alguns anos atrás, desfez de forma barulhenta a parceira de sucesso entre o roteirista Guillermo Arriaga e o diretor Alejandro González Iñárritu. ${ }^{4}$ Só para ilustrar, notemos que na tradição da indústria da telenovela no Brasil, quem assina em destaque o produto final que vai ao ar é o escritor, e não o diretor. Sob outro ângulo da questão, não podemos descartar nesses textos dramáticos a possibilidade de
4. Parceria em Amores brutos (2000), 21 Gramas (2003) e Babel (2006).

$\begin{array}{lllll}\text { EM TESE } & \text { BELO HORIZONTE } & \text { v. } 20 & \text { N. } 3 \quad \text { SET.-DEz. } 2014 & \text { CONDE. Texto, encenação e cinema }\end{array}$

\section{Crítica Literária, outras Artes e Midias}


5. Limite (Ficção, preto \& branco), 120 min., direção: Mário Peixoto. se estabelecerem, vez ou outra, como obra autônoma. Temos exemplos de roteiros de filmes clássicos ou sucessos de bilheteria publicados em livro - o que chega hoje a constituir um filão editorial - e ainda a publicação em livro de um filme nunca realizado, escrito por um diretor conhecido, fato mais raro, ou mesmo textos literários formatados como roteiros para cinema Vale lembrar que todo um campo de estudo surgiu dentro da área da Literatura Comparada a partir dessa questão, ou seja sobre o caráter literário do roteiro de cinema ou da presença do cinema na Literatura Moderna. Tudo isso para lembrar que a autonomia do texto cinematográfico ou roteiro como obra-fim, e suas fricções com a questão da sua representação, sempre existiram, mas não como no teatro, força motriz de várias transformações.

Envolto ainda nas lendas que envolviam seu único filme Limite (1931), ${ }^{5}$ poucas vezes visto mas muito cultuado, o cineasta Mário Peixoto ensaiou mais de uma vez seu retorno ao cinema. Realimentando o mistério em torno de sua obra desaparecida e da sua vida pessoal, ele, que havia desistido de dirigir várias vezes, procurou um diretor que pudesse filmar seu novo roteiro $A$ alma, segundo Salustre. Mário Peixoto teria convidado várias pessoas do cinema para a tarefa ainda nos anos 1950. Todos recusaram diante do texto, inclusive Humberto Mauro, que teria dito tratar-se de um filme muito autoral, portanto passível de ser concretizado apenas pelo próprio autor; outros, o recusaram, diante do argumento de estar ali não o roteiro, mas o próprio filme. Depois de sucessivas tentativas, o roteiro terminou sendo lançado como livro pela Embrafilme. No seu formato 'livro' acabou trazendo na capa o título: A alma, segundo Salustre - um filme de Mário Peixoto. Nos primeiros minutos do 'filme', temos o texto da cena cuja imagem se cristaliza assim:

A sala de projeção pouco a pouco é invadida de penumbra, no mais completo dos silêncios. Dos seus espectadores se ouvem apenas inquietos ruídos que produzem os assentos das cadeiras estofadas, ou os braços das mesmas, ringindo em algum movimento de acomodação procurada empreendido por seu ocupante, que procura melhor se ajeitar. $\mathrm{O}$ escuro ganhou a sala, gradativamente. E, quando é total - ouvindo-se um ou outro pigarro incontido, ou mesmo algum murmúrio de recém-chegado, atrasado, mas logo acalmado -, a tela, a grande tela do cinema, que mergulhou também nas trevas do invisível, começa a ser invadida por um longínquo ruído de asas que se debatem, sem continuidade, como um leve feixe de palhas secas, sendo açoitadas, intermitentes e nervosas, sobre alguma superfície. Por fim, após segundos, manchas coloridas e tênues começam a surgir no écran, desmaiadas em princípio, como numa nebulosa de sonho, superpondo-se no centro da tela e em determinado local fixo, com o inflar e desinflar de suas composições ainda não discernidas ou decifradas. ${ }^{6}$
6. PEIXOTO. A Alma Segundo Salustre, p. 5.
EM TESE

BELO HORIZONTE

v. 20

N. 3

SET.-DEZ. 2014

CONDE. Texto, encenação e cinema

P. $154-162$

\section{Crítica Literária, outras Artes e Midias}


7. O Homem do Morcego (1980) documentário, cor, $17 \mathrm{~min}$ direção: Ruy Solberg.
Assim prossegue o 'roteiro' chamando o leitor-espectador para um universo bem particular e quase palpável de um filme pronto, ou mesmo de imagens fílmicas presentes entre um estado imaginário e um estado real, materializadas em algum suporte 'entre' imagem e imaginado. Sob outro ângulo, o texto se apresenta como descrição de uma sucessão de imagens aparentemente reais de um filme ainda inexistente ou a descrição de um filme existente, testemunhado, mas já perdido. No exemplo dessa primeira cena não sabemos nem mesmo se o que se inicia é o próprio filme, ambientado metaliguisticamente numa sala de cinema, ou apenas o esforço poético de nos convidar, espectadores, para o filme ainda não realizado.

Numa cena do documentário sobre Mário Peixoto intitulado $O$ Homem do Morcego, ${ }^{7}$ a câmera mostra o cineasta que, olhando para a nós, narra uma cena de $A$ alma, segundo Salustre. Ele o faz com tanta veemência, e as imagens surgem com tanta força, que podemos conjecturar sobre a existência real dessa fronteira entre texto e filme, entre imagem e palavra, ou entre o roteiro, o realizador e seu gesto, o filme e sua encenação. Tarefa difícil tentar imaginar todas as possibilidades de representação de um texto, ao mesmo tempo tão exato na descrição das imagens e tão poético, podendo inclusive variar da mais pura abstração visual, dos procedimentos mais livres de representação, até os recursos mais realistas da dramatização, com outros tempos, pautados por modos de representação mais lineares. A interlocução do realizador/diretor/encenador com o roteiro cinematográfico no momento de sua representação, o grau de liberdade relativo à construção ou desconstrução do drama, ou o grau de liberdade frente a uma estrutura de imagens e sons pré-estabelecidos, determinaram também, historicamente, a possibilidade de identificar uma forma de autoria sobre o filme ou sua maior ou menor vinculação a uma estrutura institucional cinematográfica, nos domínios do experimental, do político ou do comercial. Porém, algo ainda nos parece inevitavelmente incompleto em um filme imaginado a partir do seu roteiro.

André Gaudreault, em seu livro From Plato to Lumière: narration and mostration in literature and cinema (2009), parte da fundação híbrida da prática do cinema, para abordar os diferentes tipos de narrativa que compõem o filme e, consequentemente, os diferentes narradores ou 'vozes' envolvidas na sua feitura. O autor parte da hipótese do filme como sendo o resultado da sobreposição de três campos de práticas narrativas, ligados ao literário, ao teatral e ao fílmico especificamente. Por trás desses três modos narrativos, e seus respectivos sub-narradores presentes, existe um agente maior que os agrupa em um só narrador, que ele nomeia como o 'mega-narrador' (mega narrator). As habilidades desse mega-narrador no cinema opera em três esferas: mostração (putting in place), ligada aos procedimentos miméticos da encenação
EM TESE
BELO HORIZONTE
v. 20
N. 3
SET.-DEZ. 2014
CONDE. Texto, encenação e cinema
P. $154-162$

\section{Crítica Literária, outras Artes e Midias}


teatral; mostração fílmica (putting in frame), ligada à encenação para a câmera, objeto da fotografia; e montagem fílmica (putting in sequence), sendo esta, a esfera original da narrativa cinematográfica. O filme enquanto texto, ainda no estágio de roteiro, compreende apenas uma esfera restrita desse jogo, na presença embrionária de um 'narrador textual', que opera a narrativa de forma ainda não mimética, portanto incompleta diante das camadas que demandam o filme.

Embora não seja o objetivo aqui problematizar teoricamente o filme como forma narrativa ou fenômeno de enunciação, a ideia de André Gaudreault nos lembra os diferentes domínios percorridos pelo realizador cinematográfico durante a encenação, lembrando essas diferentes 'vozes' que compõem o filme e, portanto, mais importante para nós, as diferentes habilidades demandadas para seu ofício.

Entre encenar um filme no papel, como em $A$ alma, segundo Salustre, 'imaginar' uma aparência visível das ações e dos seus lugares, torná-las uma representação fílmica na complexidade polissêmica da imagem, passando por todas as suas etapas de encenação, criando uma cena por meio das técnicas de manipulação e domínio dos procedimentos presentes em um jogo-de-cena (putting in place) e em um jogo-de-câmera (putting in frame), moldados por uma ideia de montagem (putting in sequence) é de fato o trabalho central de toda produção fílmica. A passagem do simples imaginar (o "poder interno do homem de tornar presente, por si mesmo, em pensamento, a aparência visível das coisas ausentes") para o concreto das imagens (o "poder do homem de tornar presente a aparência visível das coisas que não estão presentes, porém não mais em seu pensamento, mas na realidade exterior; não mais somente em si mesmo, mas por qualquer outro"), ${ }^{8}$ não dispõe de técnicas matemáticas e o domínio ou a segurança sobre esse processo é o trabalho do encenador, ou a verdadeira habilidade técnica e artística do diretor cinematográfico.

Portanto, em qualquer arte cênica, ou arte de representação, como no cinema ou teatro, é no 'magicar' que está o gesto essencial da fabulação cinematográfica. Adauto Novaes trata esse termo - 'magicar' - da maneira como ele é usado em Portugal, empregado "para dar conta da atividade infantil de fazer com que mundos imaginários coabitem com o mundo real". ${ }^{9}$ Termo bem coerente ao gesto de criação no cinema e ao trabalho de encenação do filme.

A presença do desenho de uma encenação em todas as etapas da construção do filme, a habilidade e domínio do processo da passagem do impalpável da imaginação, desenhada no roteiro ou na simples 'ideia de filme', para a materialidade concreta das imagens em seu devido suporte, demanda uma técnica, uma série de habilidades sobre o domínio da cena, certa interação entre um espaço, uma ação, um ator e um
8. NOVAES. Muito além do espetáculo, p. 23.
EM TESE
BELO HORIZONTE
v. 20
N. 3
SET.-DEZ. 2014
CONDE. Texto, encenação e cinema
P. 154-162

\section{Crítica Literária, outras Artes e Mídias}


10. AUMONT. O cinema e a encenação, p. 121.

11. AUMONT. O cinema e a encenação, p. 169. tempo, além da habilidade para a manipulação das qualidades e possibilidades intermediadoras da câmera. Sem esquecer que, no exercício desse processo, para além das amarras de qualquer roteiro, da cena marcada, ensaiada, devemos lembrar a presença do acaso, um dos alicerces da cena do cinema. Jacques Aumont, em seu estudo sobre cinema e encenação, aponta que

desde sempre, ou seja, desde o tempo mítico da sua invenção (cuja profecia foi realizada pelos Lumière), o cinema é um avatar do olhar móvel e indefinidamente variável; a encenação - teatro ou não, pintura ou não - foi o domínio privilegiado da efetivação desse olhar. Mas o cinema é também, de forma mais obscura, o lugar e o instrumento de um aparecimento, de improviso e em parte não dominado, de algo mais do que a vista enquadra, de algo que provém do real, que o manifesta (evidentemente sem o poder 'enquadrar'). ${ }^{10}$

O cinema inaugura em sua especificidade a possibilidade do imprevisto, parte do risco proporcionado pelo automatismo do registro da câmera, pronto em tudo apreender. O mesmo autor ainda lembra que "a encenação comporta sempre, se não um aspecto aleatório, pelo menos uma preocupação com o acidente"11 e traz o acidente para perto da questão do roteiro que consideramos anteriormente, lembrando que "a grande maioria dos cineastas, pelo menos os que trabalham na indústria, preocupa-se especialmente com o domínio e com o cálculo". ${ }^{12}$ Diante do roteiro, saber jogar o jogo, pede que o encenador cinematográfico deixe que o planejado se deixe contaminar pelos pequenos 'acidentes' do instante do set.

O documentarista Jean-Louis Comolli ao falar de um 'risco do real' inerente ao filme, trabalha seu estatuto sobre a mise-en-scène a partir da ideia de que:

em sua parte documentária - que é a marca de seu nascimento e a condição de sua invenção -, o cinema nada faz além de abrir o diafragma de uma lente, a sensibilidade de uma emulsão, a duração de uma exposição, o tempo de uma passagem, à presença luminosa do outro, mais ou menos - toda a questão está nessa gradação -, desse outro que vem à câmera tanto quanto ela vem a ele. ${ }^{13}$

Antevisto no roteiro, "o sonho de um filme", ${ }^{14}$ como define Jean-Claude Carrière, e construído pelo 'em processo' da etapa de preparação, o momento da mise-en-scène para a câmera ou do trabalho do seté que constitui, assim, o grande momento de construção do filme, ou pelo menos o momento chave a ser dominado. Mise-en-scène ou 'encenação' são termos comuns, que se justificam aqui dentro da proposta de abordagem da fabricação do filme por lembrarem as
12. AUMONT. O cinema e a encenação, p. 170.

13. COMOLLI. Ver e poder, p. 13

14. CARRIÈRE. Prática do roteiro cinematográfico, p. 59.
EM TESE
BELO HORIZONTE
v. 20
N. 3
SET.-DEZ. 2014
CONDE. Texto, encenação e cinema
P. 154-162

\section{Crítica Literária, outras Artes e Mídias}


aproximações e atritos dos procedimentos nos campos de criação do teatro e do cinema, e que servem, mais uma vez, para destacar a necessidade de se fazer reconhecer o convívio de habilidades técnicas e artísticas híbridas no realizador. O 'set é um termo traduzido no Dicionário Houaiss como cenário, conjunto, jogo, série, configuração, aparelho, solidificação, conhecido também no Brasil como 'platô', do francês plateau, termo que reúne os dois espaços lembrados aqui palco e set. De acordo com o Dicionário Larrousse 'plateau' significa: palco de teatro, estúdio de cinema ou televisão, local onde são montados os cenários e onde performam os atores.

\section{REFERÊNCIAS}

AUMONT, Jacques. $\mathbf{O}$ cinema e a encenação. Lisboa:

Texto\&Grafia, 2006

CARRIÈRE, Jean Claude. A linguagem secreta do cinema. Rio de Janeiro: Nova Fronteira, 1994.

FIELD, Syd. Manual do roteiro. Rio de Janeiro: Objetiva, 1982.

GAUDREAULT, André. From Plato to Lumière: narration and mostration in literature and cinema. Toronto: University of Toronto Press, 2009.

NOVAES, Adauto (org). Muito além do espetáculo. São Paulo: Editora SENAC, 2005.
PEIXOTO, Mário. A alma, segundo Salustre. Rio de Janeiro: Embrafilme/DAC, 1983.

ROUBINE, Jean-Jacques. Introdução às grandes teorias do teatro. Rio de Janeiro: Jorge Zahar, 2003.

\section{FILMOGRAFIA}

Limite, Ficção, preto \& branco, 120 min., 1931, direção: Mário Peixoto.

O Homem do Morcego, documentário, cor, 17 min., 1980 direção: Ruy Solberg. 